INVESTIGATION OF A POSSIBLE ASSOCIATION BETWEEN KIF1A GENE AND MICROCEPHALY IN ZIKA-DENGUE COINFECTED PATIENT

\title{
ORIGIN OF PROPOSAL
}

People living in Columbia \& brazil are experiencing ZIKA-DENGUE coinfection from last few years[1]. After infecting some patients are asymptomatic, few of them are showing mild symptoms \& some of them are experiencing serious neurological issues. The situation become more challenging if any pregnant woman coinfected by DENGUE-ZIKA at the same time, the neonatal may develop microcephaly (A neurological developmental disorder). The reason behind this is not clear yet \& no such treatment is established to treat the neuronal complications. It is established that microcephaly is a genetic disease \& KIF1A gene is responsible for this. I would like to investigate about this particular phenomenon and will try to give a new concept, which can be used for future treatment.

\section{LITERATURE}

Recently Dengue, Zika coinfection became the cause of national surveillance in Colombia [1]. Both viruses belong to the flavi-virus and usually cocirculate within the same area. Main causative agent is Aedes aegypti[2]. There are four different serotypes are present of dengue virus(i.e.-DENV 1-4)[3].In India dengue serotype type 1 and type 3 are dominant during 2017. Mainly affected areas are pune, Nashik region of Maharashtra, western India[4]. Till now ZIKA has only one serotype[5]. It is interesting that a single person can be infected by 4 serotypes of ZIKA virus and dengue virus. The symptoms are fever, loss of smell, rashes in skin and in some cases neurological manifestation. In India people have done genotypic characterization of serotypes of DENV virus[6]. Computational analysis also done in case of ZIKA serotypes[7]. After that sequence alignment was done, it is found that in between this two viruses there is $70 \%$ similarity in their respective sequence. When two virus attack an individual the a phenomenon known as "antibody dependent enhancement' is triggered. This phenomenon will help sometimes to spread the infection [8]. Antibody dependent enhancement may effect the brain and can cause severe neurological problem. This mechanism can effect neurodevelopmental issues. At present, new insights of neuro-inflammation offering a great opportunity to investigate potential therapeutic targets[9]. It is established from the serological 
diagnosis that ZIKA DENV coinfection may cause neurological manifestation. Some patients lives in Brazilian region experiences some serious neurological manifestation like GBS,microcephaly etc. Zika dengue coinfection is responsible for this[10]. Microcephaly is a genetic disease and it is established that de novo mutation of a specific gene may lead to neurodevelopmental disease[11]. KIF1A gene may be responsible for microcephaly in those coinfected patients. KIF1A helps to drive interkinetic nuclear cell migration of Brain neural stem cell[RGP]. Neurons are generated from asymmetric cell division. After cell division it migrates to the subventricular zone (SVZ) and lower intermediate zone (IZ). After that neurons became multipolar [12]. Then the transition from multipolar to bipolar takes place and they migrate from along the basal process of neighboring RGP cells to cortical plate[13-14]. It is also established that microtubular motor proteins KIF1A and dynein both are responsible for basal and apical INM in rat brain RGP cells [15-16]. On the other hand, It is also established that inhibition of basal INM by KIF1A must have influence on subsequent brain development. Neuronal distribution was also altered [17-18]. Mutation in the gene encoding the cytoplasmic dynein resulted in accumulation of post-mitotic neurons in the multipolar state and also the migration of bipolar neurons to cortical plate was also blocked. This effect can result in microcephaly[19-23].Till now human KIF1A mutation have been found to cause different types of neuropathies. The relationship between the brain malformations and KIF1A gene is poorly understood [24-30]. It is also established that knockdown of KIF1A gene can decrease neurogenic division. In another study researchers proved that KIF1A knockdown can inhibit multipolar-bipolar transition. It is also established by by a group of researchers using deep sequencing method that KIF1A is responsible for frontal pachygyria [31]. When researchers are trying to find out the relation between BDNF and KIF1A, they discover that it participate in vesicular transport in non-neuronal and neuronal cells. BDNF stands for brain derived neurotropic factor. There is a well established pathway known as KIF1A-BDNF-DCX pathway. DCX stands for neuronal migration protein doublecortin. Doublecortin is unique MAP and DCX is determinant factor in growth, dendritic extension, neuclear translocation and it also prevents nucleokinesis defects[32-33]. It is also established that altered KIF1A expression might potentially interfere with growth factor transport and secretion. BDNF is also under the control of KIF1A gene[34]. It is expressed in the neurocortex throughout the brain development [35] and also reported to accelerate the redistribution of neurons [36]. As far we know that KIF1A is a classical N-terminal motor protein. It has three coiled coils, a stalk domain in the middle part and a pleckstrin homology. In C.elegans it is established that it helps for the recognition of phosphophatidyl 4,5-bisphosphate (PIP2) in cargo vesicle membrane. As 
per data observed, The stalk region is highly similar to MAGUK binding site(MAGUK site also found in other kinesin motors, like KIF13B)[39]. It is also identified that the mutation in any tubulin, motor protein isoform supports the view of defective cargo transport and it can lead to neurodegeneration [40].As per study, KIF1A was first identified as motor proteins for synaptic vesicles and DCV[41-42]. KIF1A has two scaffolding protein. 1. TANC2 and 2. Liprin- $\alpha$. These scaffolding proteins interacts with the tail region of KIF1A [43]. It is established that $\mathrm{Ca}+2 / \mathrm{CAM}$ regulates KIF1A molecular dynamics. TANC2 and liprin- $\alpha$ has an established role in KIF1A dependent cargo trafficking. $\mathrm{Ca}+2 / \mathrm{CAM}$ interacts with KIF1A , allows DCV binding and motility[44][46]. Neurofascin is a L1 family immunoglobulin cell adhesion molecule involved in subcellular targeting and synapse formation during neuronal development[47]. 


\section{IDENTIFICATION OF THE LACUNAE IN UNDERSTANDING}

Neurofascin is an intermediate of the DCX pathway [45] and it may have effect in the microcephaly. There is no established work about the role of neurofascin in microcephaly.

$>$ The role of TANC2 and liprin- $\alpha$ in the development of microcephaly is not established yet. 


\section{HYPOTHESIS}

My hypothesis is TANC2 and liprin- $\alpha$ may be coregulated (enhancing or supressing the activity of each other) and this coregulation may have specific role in the development of microcephaly. To establish this, I have done promoter analysis of both genes (which encode above mentioned proteins) and found similarity in the promoter sequence. The results are shown below in the given diagram: -

\begin{tabular}{rrrr}
\multicolumn{4}{c}{ PRONOTER ANALYSIS OF LIPRIN-Q } \\
Start & End & Score & Promoter Sequence \\
28 & 78 & 0.81 & GACTGGGGCGGGGGCCGGGGCACGGCGTGGGGCGGGCAGGCGGACGC \\
1253 & 1303 & 0.98 & CAGACTGAAGATAAAAACCGCCAGTTACAGGAGCGCTTGGAATTGGCAGA \\
2433 & 2483 & 0.80 & ACCGGCTGCACAAAGGGGCGTGCACACCGTTAGCCACGAGGACATCAGG \\
2883 & 2933 & 0.91 & GAGCAAACGTGAAAAGCGGGGCCATCATGTCGGCCCTGTCCGACACAGAG \\
4122 & 4172 & 0.93 & TGCTTGTATGTATAAATCCTATGAATAGAGGGCTTTTGAAATTATGCAT \\
4218 & 4268 & 0.95 & ATTTTACGTTTATAAAATTATGACAGAAGCCATGTGCATTATCCTTACG \\
4390 & 4440 & 0.84 & ATGAACAGATTTAAAATGGCTGGTGTTAAATATCAGCTCCTAATAAGATG \\
4762 & 4812 & 0.84 & GTGCAGCTCTAATAAAGGCCTTATTTTTCTTATGTAAATCATCTTTTTAC \\
4917 & 4967 & 0.83 & TTAAATGGCATATTAACAAGCCAGCAAAGTGTGTCAGACCATGGCGTGGT
\end{tabular}

PROMOTER ANALYSIS TANC2

Promoter predictions for NM_025185.4:1-1000 :

Start End Score Promoter Sequence

$\begin{array}{llll}181 & 231 & 0.81 & \text { TTCGGGCGGCCCCGCCCCCATTCCCATCCCCCTCGCGCTCACCTCCCGGC }\end{array}$

MULTIPLE SEQUENCE ALIGNMENT RESULT

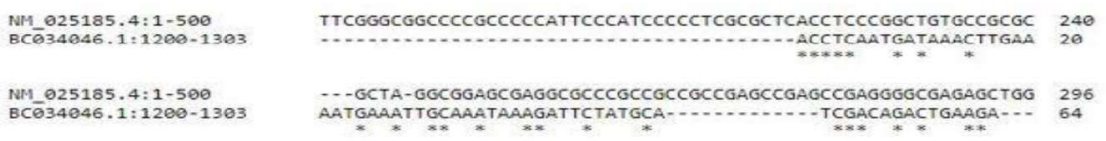




\section{OBJECTIVES (IN 2 YEARS TIME FRAME)}

The objectives of my project are furnished below: -

To investigate the relation between neurofascin pathway and KIF1A gene and to establish the role of neurofascin in microcephaly.

$>$ To investigate the coregulation in between liprin $\alpha$, TANC2 protein.

$>$ To investigate the relationship between liprin- $\alpha$ and TANC2 coregulation and microcephaly. 


\section{WORKPLAN}

\section{TO INVESTIGATE THE RELATION BETWEEN NEUROFASCIN PATHWAY AND KIF1A GENE AND TO ESTABLISH THE ROLE OF NEUROFASCIN IN MICROCEPHALY}

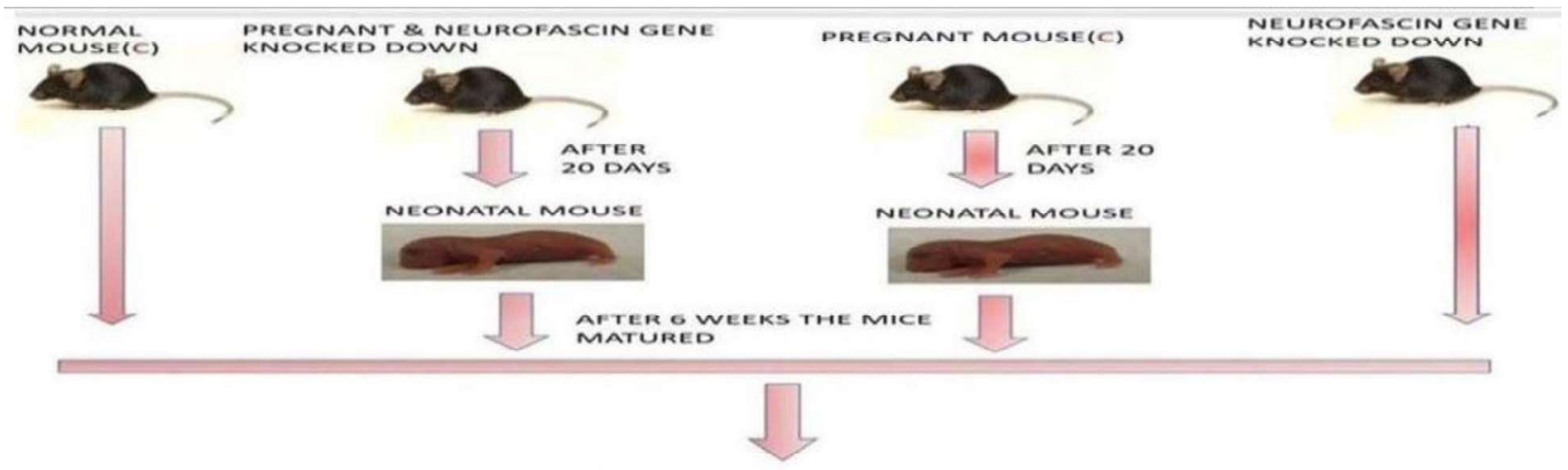

MICE ARE SACRIFICED

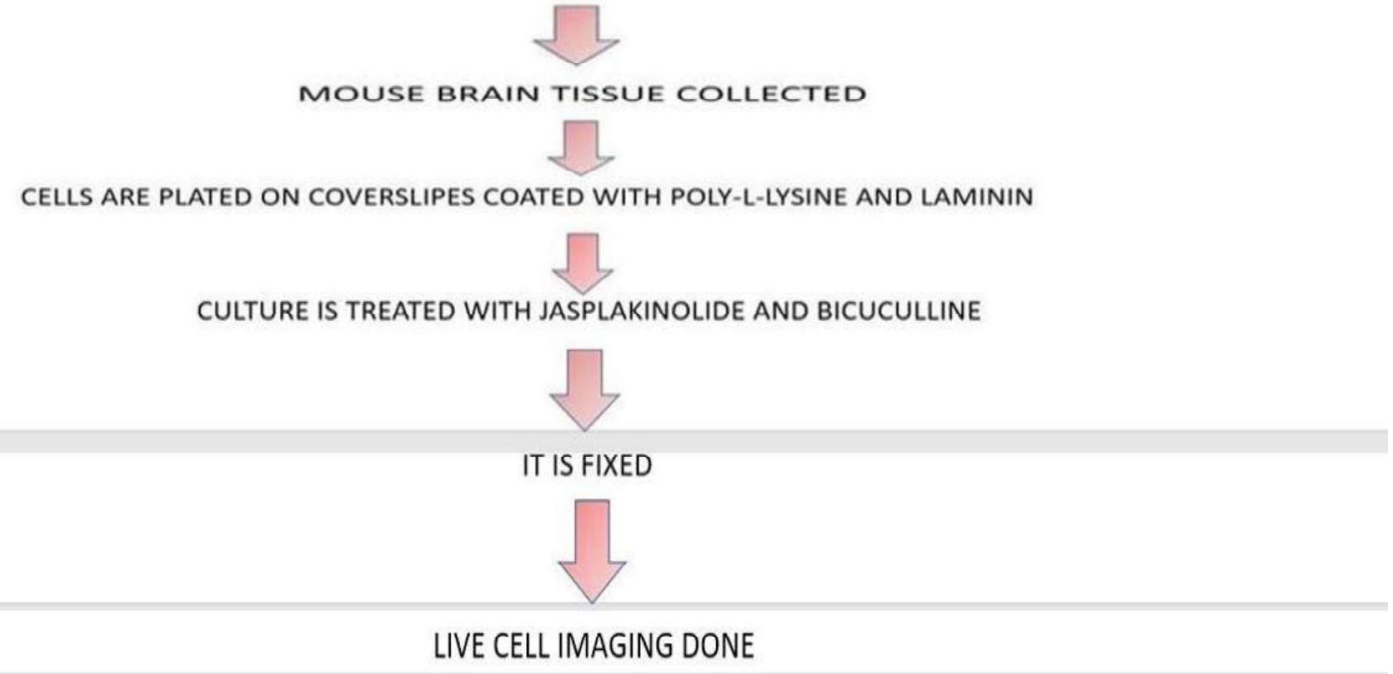

HERE, $\quad \mathrm{C}=\mathrm{CONTROL}$

In the above mentioned experiment neurofascin gene has to be knocked down in a pregnant mouse and in normal mouse. After the pregnant mouse give birth to the neonatal mouse, then the brain tissue of the neonatal and neurofascin knocked down mice has to be collected. The cells have to be cultured and live cell imaging has to be done. From the live cell imaging if it is observed any abnormal neuronal development compared with the control one then it can be concluded that neurofascin may have effect in microcephaly. 
FUNCTION OF REAGENT AND MATERIALS USED

\begin{tabular}{|l|l|}
\hline NAME OF THE REAGENT & FUNCTION \\
\hline LATRUNCULIN B & $\begin{array}{l}\text { It causes concentration dependent changes in } \\
\text { cell shape and microtubule (e.g.- actin) } \\
\text { organization }\end{array}$ \\
\hline JASPLAKINOLIDE & An agent which stabilize filament polymers \\
\hline BICUCULLINE & $\begin{array}{l}\text { It has been used to investigate a sudden } \\
\text { uncontrolled electrical disturbance in brain }\end{array}$ \\
\hline
\end{tabular}

\section{TO INVESTIGATE THE COREGULATION BETWEEN TANC2 AND LIPRIN- $\alpha$}

IN VITRO TRANSCRIPTION ASSAY USING LUCIFERASE REPORTER GENE TO ESTABLISH THE COREGULATION BETWEEN TANC2 AND LIPRIN- $\alpha$

The experimental procedure is as follows: -

1. TANC2(Tetratricopeptide repeat, ankyrin repeat and coiled-coil containing 2) and LIPRIN- $\alpha$, both proteins are purified. The purification procedure is discussed in the mentioned literature (REF NO-46))

2. A construct is produced in which the regulatory region of the target gene (e.gTANC2) is fused with DNA coding sequence of luciferase.

3. A separate DNA construct which encodes the protein liprin- $\alpha$ is also prepared (To study the effect of that particular protein in transcription of TANC2)

4. A neuronal cell culture is taken and it is transfected by both the constructs.

5. If the protein (Liprin- $\alpha$ ) able to upregulate transcription of the target gene, the cell will express luciferase. 
6. Examination of the expression of luciferase has to be done about 2-3 days after initial cell expression.

7. Cells were lysed and all the contents are placed in a reaction tube.

8. Proper substrate for luciferase (e.g. D-luciferin, coelenterazine) is added. Luciferase will catalyse the reaction in the reaction tube.

9. The light is detected with luminometer and amount of light produced provides a quantative measure of the effect of the protein on the expression of the target gene.

The experiment is repeated with liprin- $\alpha$ coding gene as a target one and TANC2 as an effector. The diagram of the gene is given below:-

\section{IN VITRO TRANSCRIPTION ASSAY USING LUCIFERASE REPORTER}

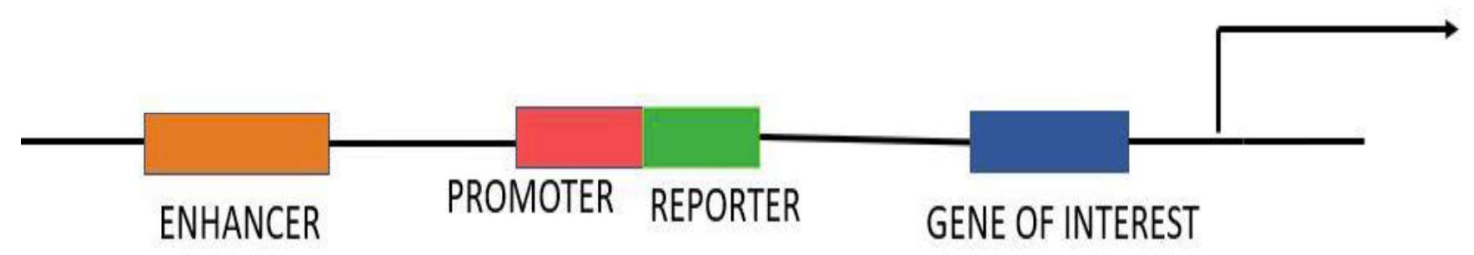

TRANSCRIPTION ACTIVATORS OF TANC2 - SP1,AP-2,ETF,WT1,Adf-1,GATA-1,NF-1,SRF,HNF-3,T3R,TtX ETC. TRANSCRIPTION ACTIVATORS OF LIPRIN ALPHA - Egr-1,p1, Iph,E1,Elf-1,Elk-1 


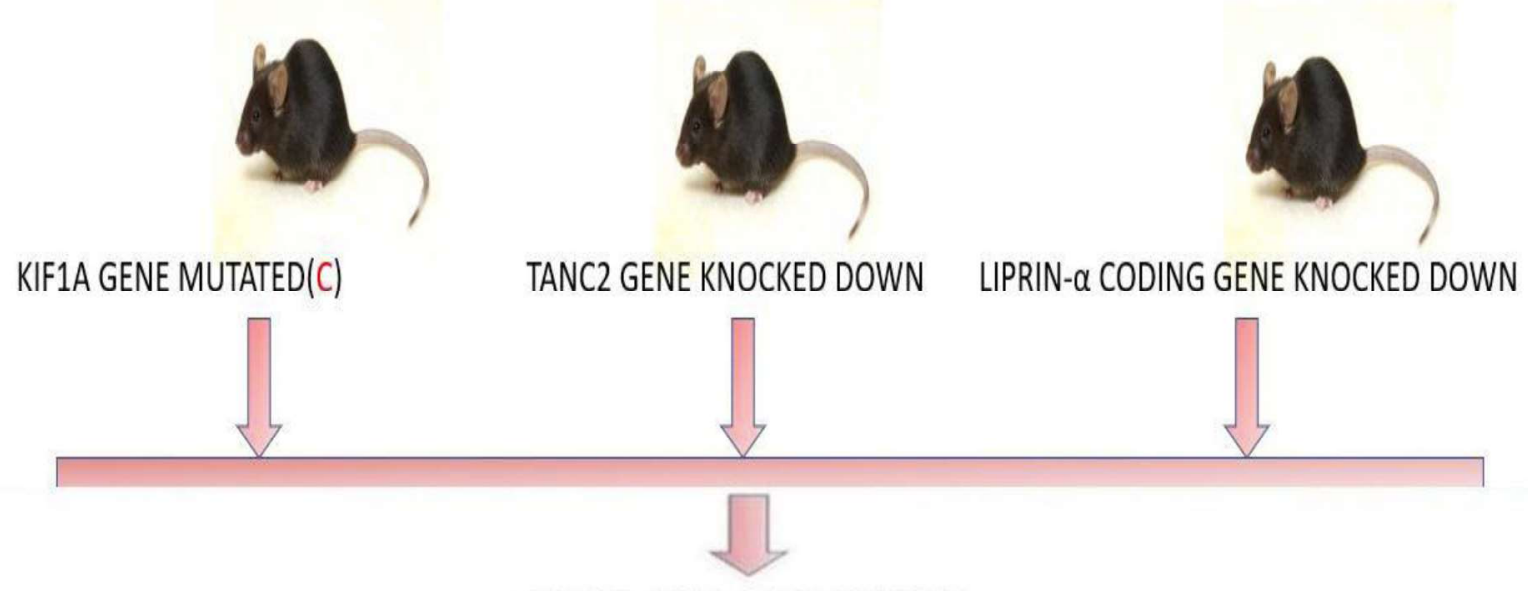

MICE ARE SACRIFICED

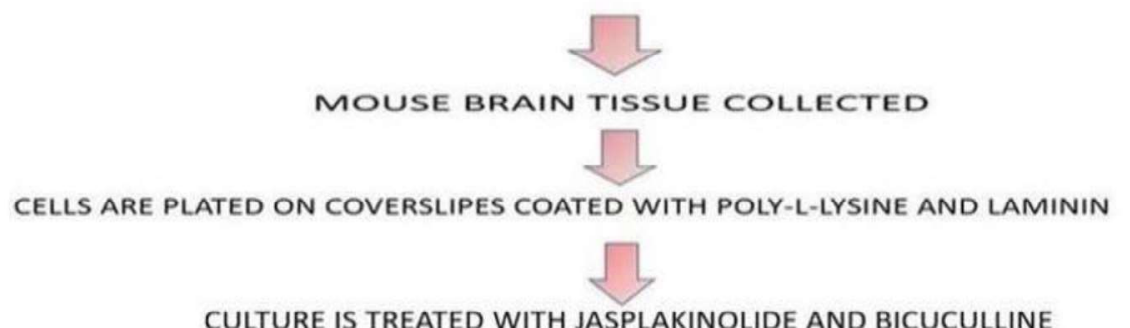

CULTURE IS TREATED WITH JASPLAKINOLIDE AND BICUCULLINE

IT IS FIXED

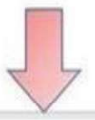

LIVE CELL IMAGING DONE

In the above-mentioned experiment three mice are taken. From the literature survey, it is known that KIF1A gene is responsible for microcephaly. So, KIF1A gene is mutated in a mouse and it is considered as control one. In rest of the mouse TANC2 and liprin- $\alpha$ coding gene "knocked down", then mouse brain tissue is collected and cultured. After that live cell imaging is done. From live cell imaging we can do comparative study on neuronal development. Comparative study of life cell imaging will give us an idea about the severity of the disease (associated with TANC2 and LIPRIN- $\alpha$ ) . 


\section{SIGNIFICANCE}

Till now, it is known that microcephaly is a genetic disorder and KIF1A gene is responsible for this. It is not investigated till now that how neurofascin pathway helps to develop microcephaly and role of TANC2, liprin- $\alpha$ coregulation in microcephaly. To find out these answers, three investigation has been proposed and from that output we can develop future plans for investigation in that particular field. From the above-mentioned experiments, if it is established that neurofascin has role in microcephaly then we can use any potential lead molecule which will inhibit that pathway and may have an effective role in treatment of microcephaly. Similarly, if it is established the coregulation in between TANC2 and liprin- $\alpha$ then we can design drug molecules which will supress the activity of the enhancer and can be used as an alternative treatment of microcephaly. This project will make a foundation towards the development of therapeutic and medicinal approaches of microcephaly and lots of work can be proposed based on the result of this project.

\section{ABBREVATIONS}

\begin{tabular}{|l|l|}
\hline INM & Interkine nuclear migration \\
\hline RGP & Radial glial progenitor \\
\hline SVZ & Subventricular zone \\
\hline IZ & Lower intermediate zone \\
\hline SNP & Short neural precursors \\
\hline IP & Intermediate progenitor \\
\hline DCV & Secretary vesicles \\
\hline SV & Synaptic vesicles \\
\hline TANC2(NCBI ID-26115) & $\begin{array}{l}\text { Tetracopeptide repeat, ankyrin repeat } \\
\text { and coiled coil containing 2 }\end{array}$ \\
\hline
\end{tabular}

\section{ACKNOWLEDGEMENT}

I am thankful to and fortunate enough to get constant encouragement, support and guidance from all respected professors of department of biochemistry, university of Calcutta which helped me in successfully completing project work. 


\section{REFERENCE}

[1]Mercado-Reyes M, Acosta-Reyes J, Navarro-Lechuga E, et al. Dengue, chikungunya and zika virus coinfection: results of the national surveillance during the zika epidemic in Colombia. Epidemiol Infect. 2019;147:e77.

[2]Tang B, Zhou WK, Xiao YN, Wu JH. Implication of sexual transmission of Zika on dengue and Zika outbreaks. Math Biosci Eng. 2019;16(5):5092-5113.

[3] Soo KM, Khalid B, Ching SM, Chee HY. Meta-Analysis of Dengue Severity during Infection by Different Dengue Virus Serotypes in Primary and Secondary Infections. PLoS One. 2016;11(5):e0154760. Published 2016 May 23.

[4] Patil JA, Alagarasu K, Kakade MB, et al. Emergence of dengue virus type 1 and type 3 as dominant serotypes during 2017 in Pune and Nashik regions of Maharashtra, Western India. Infect Genet Evol. 2018;66:272-283.

[5]Lowe R, Barcellos C, Brasil P, et al. The Zika Virus Epidemic in Brazil: From Discovery to Future Implications. Int J Environ Res Public Health. 2018;15(1):96. Published 2018 Jan 9.

[6] Chetry S, Khan SA, Dutta P, et al. Dengue virus serotypes and genotypic characterization from northeast India. J Med Virol. 2019;91(6):918-927.

[7] Fonseca V, Libin PJK, Theys K, et al. A computational method for the identification of Dengue, Zika and Chikungunya virus species and genotypes. PLoS Negl Trop Dis. 2019;13(5):e0007231. Published 2019 May 8.

[8]Tang B, Xiao Y, Sander B, Kulkarni MA, Radam-Lac Research Team, Wu J. Modelling the impact of antibody-dependent enhancement on disease severity of Zika virus and dengue virus sequential and co-infection. R Soc Open Sci. 2020;7(4):191749. Published 2020 Apr 15.

[9] Ransohoff RM, Schafer D, Vincent A, Blachère NE, Bar-Or A. Neuroinflammation: Ways in Which the Immune System Affects the Brain. Neurotherapeutics. 2015;12(4):896-909. doi:10.1007/s13311-015-0385-3

[10]Raboni SM, Bonfim C, Almeida BM, et al. Flavivirus cross-reactivity in serological tests and Guillain-Barré syndrome in a hematopoietic stem cell transplant patient: A case report. Transpl Infect Dis. 2017;19(4):10.1111/tid.12700.

[11] Coe BP, Stessman HAF, Sulovari A, et al. Neurodevelopmental disease genes implicated by de novo mutation and copy number variation morbidity. Nat Genet. 2019;51(1):106-116.

[12]Noctor SC, Martínez-Cerdeño V, Ivic L, Kriegstein AR. Cortical neurons arise in symmetric and asymmetric division zones and migrate through specific phases. Nat Neurosci. 2004; 7(2):136-144. 
[13]Kriegstein A, Alvarez-Buylla A. The glial nature of embryonic and adult neural stem cells. Annu Rev Neurosci. 2009;32:149-184.

[14]Lazutkin A, Podgorny O, Enikolopov G. Modes of division and differentiation of neural stem cells. Behav Brain Res. 2019;374:112118.

[15] Schuster M, Kilaru S, Fink G, Collemare J, Roger Y, Steinberg G. Kinesin-3 and dynein cooperate in long-range retrograde endosome motility along a nonuniform microtubule array. Mol Biol Cell. 2011;22(19):3645-3657.iate interkinetic nuclear migration in neural stem cells. Nat Neurosci. 2010;13:1463-1471

[16] Hu DJK, et al. Dynein recruitment to nuclear pores activates apical nuclear migration and mitotic entry in brain progenitor cells. Cell. 2013;154:1300-1313.

[17]Tsai JW, Lian WN, Kemal S, Kriegstein AR, Vallee RB. Kinesin 3 and cytoplasmic dynein mediate interkinetic nuclear migration in neural stem cells. Nat Neurosci. 2010;13:1463-1471

[18] Liu JS, et al. Molecular basis for specific regulation of neuronal kinesin-3 motors by doublecortin family proteins. Mol Cell. 2012;47:707-721.

[19]Lipka J, Kuijpers M, Jaworski J, Hoogenraad CC. Mutations in cytoplasmic dynein and its regulators cause malformations of cortical development and neurodegenerative diseases. Biochem Soc Trans. 2013;41:1605-1612.

[20]Poirier K, et al. Mutations in TUBG1, DYNC1H1, KIF5C and KIF2A cause malformations of cortical development and microcephaly. Nature Genetics. 2013

[21]Alkuraya FS, et al. Human mutations in NDE1 cause extreme microcephaly with lissencephaly [corrected] Am J Hum Genet. 2011;88:536-547

[22]Fiorillo C, et al. Novel dynein DYNC1H1 neck and motor domain mutations link distal spinal muscular atrophy and abnormal cortical development. Hum Mutat. 2014;35:298-302.

[23]Dobyns WB, Reiner O, Carrozzo R, Ledbetter DH. Lissencephaly. A human brain malformation associated with deletion of the LIS1 gene located at chromosome 17p13. JAMA. 1993;270:2838-2842.

[24]Klebe S, et al. Autosomal recessive spastic paraplegia (SPG30) with mild ataxia and sensory neuropathy maps to chromosome 2q37.3. Brain. 2006;129:1456-1462

[25]Erlich Y, et al. Exome sequencing and disease-network analysis of a single family implicate a mutation in KIF1A in hereditary spastic paraparesis. Genome Res. 2011;21:658-664.

[26]Klebe S, et al. KIF1A missense mutations in SPG30, an autosomal recessive spastic paraplegia: distinct phenotypes according to the nature of the mutations. Eur $\mathrm{J}$ Hum Genet. 2012;20:645-649. 
[27]Rivière J-B, et al. KIF1A, an axonal transporter of synaptic vesicles, is mutated in hereditary sensory and autonomic neuropathy type 2. Am J Hum Genet. 2011;89:219-230.

[28]Hamdan FF, et al. Excess of de novo deleterious mutations in genes associated with glutamatergic systems in nonsyndromic intellectual disability. Am J Hum Genet. 2011;88:306316

[29]Jamuar SS, et al. Somatic mutations in cerebral cortical malformations. N Engl J Med. 2014;371:733-743

[30]Esmaeeli Nieh S, et al. De novo mutations in KIF1A cause progressive encephalopathy and brain atrophy. Ann Clin Transl Neurol. 2015;2:623-635.

[31] Jamuar SS, et al. Somatic mutations in cerebral cortical malformations. N Engl J Med. 2014;371:733-743.

[32]Xue X, Jaulin F, Espenel C, Kreitzer G. PH-domain-dependent selective transport of p75 by kinesin-3 family motors in non-polarized MDCK cells. J Cell Sci. 2010;123:1732-1741.

[33] Okada Y, Yamazaki H, Sekine-Aizawa Y, HIROKAWA N. The neuron-specific kinesin superfamily protein KIF1A is a unique monomeric motor for anterograde axonal transport of synaptic vesicle precursors. Cell. 1995;81:769-780.

[34]Kondo M, Takei Y, Hirokawa N. Motor protein KIF1A is essential for hippocampal synaptogenesis and learning enhancement in an enriched environment. Neuron. 2012;73:743-757.

[35]Fukumitsu $\mathrm{H}$, et al. Simultaneous expression of brain-derived neurotrophic factor and neurotrophin-3 in Cajal-Retzius, subplate and ventricular progenitor cells during early development stages of the rat cerebral cortex. NSC. 1998;84:115-127

[36]Behar TN, et al. Neurotrophins stimulate chemotaxis of embryonic cortical neurons. Eur J Neurosci. 1997;9:2561-2570

[37]Bai $\mathrm{J}$, et al. RNAi reveals doublecortin is required for radial migration in rat neocortex. Nat Neurosci. 2003;6:1277-1283.

[38]Klopfenstein D.R.Tomishige M.Stuurman N.Vale R.D.Role of phosphatidylinositol $(4,5)$ bisphosphate organization in membrane transport by the Unc104 kinesin motor.Cell. 2002; 109: 347-358

[39]Hanada T.Lin L.Tibaldi E.V.Reinherz E.L.Chishti A.H.GAKIN, a novel kinesin-like protein associates with the human homologue of the Drosophila discs large tumor suppressor in $\mathrm{T}$ lymphocytes.J. Biol. Chem. 2000; 275: 28774-28784

[40]Millecamps S.Julien J.P.Axonal transport deficits and neurodegenerative diseases.Nat. Rev. Neurosci. 2013; 14: 161-176

[41]Niwa S.Tanaka Y.Hirokawa N.KIF1Bbeta- and KIF1A-mediated axonal transport of presynaptic regulator Rab3 occurs in a GTP-dependent manner through DENN/MADD.Nat. Cell Biol. 2008; 10: 1269-1279 
[42]Lo K.Y.Kuzmin A.Unger S.M.Petersen J.D.Silverman M.A.KIF1A is the primary anterograde motor protein required for the axonal transport of dense-core vesicles in cultured hippocampal neurons.Neurosci. Lett. 2011; 491: 168-173

[43]Shin H.Wyszynski M.Huh K.H.Valtschanoff J.G.Lee J.R.Ko J.Streuli M.Weinberg R.J.Sheng M.Kim E.Association of the kinesin motor KIF1A with the multimodular protein liprinalpha.J. Biol. Chem. 2003; 278: 11393-11401

[44]Niwa S.Lipton D.M.Morikawa M.Zhao C.Hirokawa N.Lu H.Shen K.Autoinhibition of a neuronal kinesin UNC-104/KIF1A regulates the size and density of synapses.Cell Rep. 2016; 16: 2129-2141

[45] http://www.pathwaycommons.org/pc/record2.do?id=485263

[46]Stucchi R, Plucińska G, Hummel JJA, et al. Regulation of KIF1A-Driven Dense Core Vesicle Transport: $\mathrm{Ca}^{2+} / \mathrm{CaM}$ Controls DCV Binding and Liprin- $\alpha /$ TANC2 Recruits DCVs to Postsynaptic Sites. Cell Rep. 2018;24(3):685-700. doi:10.1016/j.celrep.2018.06.071

[47] Efthymiou S, Salpietro V, Malintan N, et al. Biallelic mutations in neurofascin cause neurodevelopmental impairment and peripheral demyelination. Brain. 2019;142(10):2948-2964.

[48]Transcription activator of TANC2:-

http://gene-regulation.com/cgi-bin/pub/programs/alibaba2/webbaba2.cgi 
